\title{
Fate of Crude Oil in the Environment and Remediation of Oil Spills
}

\author{
Lauren Iskander ${ }^{1}$, Charbel Abou Khalil ${ }^{2}$, Michel C. Boufadel*22 \\ ${ }^{1}$ Academy of Saint Elizabeth \\ ${ }^{2}$ Center for Natural Resources, Department of Civil and Environmental Engineering, New Jersey Institute of Technology
}

\section{INTRODUCTION}

The world consumes approximately 5.1 billion tons of crude oil per year, with the United States and Saudi Arabia producing the largest shares [1]. Countries rely on various means for transporting crude oil [1, 2]. Large vessel/tankers transport oil at sea, while oil is transported inland via pipelines, railroads, trucks, and barges [2].

Unfortunately, some of the oil gets spilled into the ocean, freshwater bodies, and terrestrial ecosystems during its production, transportation, and use [3]. Usually, oil spills are caused by accidents involving tankers, barges, pipelines, refineries, drilling rigs, and storage facilities [3]. Small spills are frequent, but are handled by local responders. However, in the case of relatively large spills, known as spills of national significance, a national effort is needed to respond. Examples of large spills include the running aground of the Exxon Valdez in Alaska and the Deepwater Horizon blowout in the Gulf of Mexico. These spills triggered the application of the Oil Pollution Act of 1990 and ensuing regulations [4-9].

When an oil spill reaches the shoreline, efforts are taken to remove as much of the oil as possible using physical means, such as water flushing [3]. When the oil content within sediments becomes too low, physical removal becomes inefficient and/or can lead to further damage [3]. In this situation, oil biodegradation, that is the degradation of oil mediated by microorganisms, becomes an important process to consider [10]. Beaches are bioremediated by monitoring and enhancing the biodegradation of oil. Critically understanding and analyzing oil biodegradation and remediation techniques allows for a better response by decision-makers.

This paper first addresses the general chemical composition of oils and then covers the different physical and natural processes that can remove crude oil from beaches, with a focus on bioremediation.

Table 1. Chemical characteristics of a few hydrocarbons present in crude oil.

\begin{tabular}{|c|c|c|c|c|}
\hline $\begin{array}{c}\text { Name of } \\
\text { hydrocarbon }\end{array}$ & $\begin{array}{l}\text { Molecular } \\
\text { formula }\end{array}$ & $\begin{array}{c}\text { Type of } \\
\text { hydrocarbon }\end{array}$ & $\begin{array}{l}\text { Chemical } \\
\text { structure }\end{array}$ & $\begin{array}{c}\text { Molecular } \\
\text { weight }(\mathrm{g} / \mathrm{mol})\end{array}$ \\
\hline Hexane & $\mathrm{C}_{6} \mathrm{H}_{14}$ & Alkane & & 86.18 \\
\hline Methylpentane & $\mathrm{C}_{6} \mathrm{H}_{14}$ & $\begin{array}{l}\text { Branched } \\
\text { alkane }\end{array}$ & & 86.18 \\
\hline Cyclohexane & $\mathrm{C}_{6} \mathrm{H}_{12}$ & Cycloalkane & & 84.16 \\
\hline Benzene & $\mathrm{C}_{6} \mathrm{H}_{6}$ & BTEX & & 78.11 \\
\hline $\begin{array}{l}\text { Phenanthrene } \\
\text { (three fused } \\
\text { benzene rings) }\end{array}$ & $\mathrm{C}_{14} \mathrm{H}_{10}$ & PAH & & 178.23 \\
\hline
\end{tabular}




\section{INTRODUCTION}

The world consumes approximately 5.1 billion tons of crude oil per year, with the United States and Saudi Arabia producing the largest shares [1]. Countries rely on various means for transporting crude oil [1, 2]. Large vessel/tankers transport oil at sea, while oil is transported inland via pipelines, railroads, trucks, and barges [2].

Unfortunately, some of the oil gets spilled into the ocean, freshwater bodies, and terrestrial ecosystems during its production, transportation, and use [3]. Usually, oil spills are caused by accidents involving tankers, barges, pipelines, refineries, drilling rigs, and storage facilities [3]. Small spills are frequent, but are handled by local responders. However, in the case of relatively large spills, known as spills of national significance, a national effort is needed to respond. Examples of large spills include the running aground of the Exxon Valdez in Alaska and the Deepwater Horizon blowout in the Gulf of Mexico. These spills triggered the application of the Oil Pollution Act of 1990 and ensuing regulations [4-9].

When an oil spill reaches the shoreline, efforts are taken to remove as much of the oil as possible using physical means, such as water flushing [3]. When the oil content within sediments becomes too low, physical removal becomes inefficient and/or can lead to further damage [3]. In this situation, oil biodegradation, that is the degradation of oil mediated by microorganisms, becomes an important process to consider [10]. Beaches are bioremediated by monitoring and enhancing the biodegradation of oil. Critically understanding and analyzing oil biodegradation and remediation techniques allows for a better response by decision-makers.

This paper first addresses the general chemical composition of oils and then covers the different physical and natural processes that can remove crude oil from beaches, with a focus on bioremediation.

\section{OIL COMPOSITION AND CLASSIFICATION}

Crude oil is composed of thousands of chemical compounds, which can be classified into four major groups: saturates, aromatics, resins, and asphaltenes (SARA). Generally, Crude oil differs in composition when extracted from different reservoirs [4]. Even oil extracted from the same well can produce samples with distinct SARA fractions [4].

Saturates (saturated hydrocarbons), which possess single chemical bonds, make up about $60 \%$ of most crude oils [11].
There are three types of saturates in crude oil: straight-chain alkanes (linear structures), cycloalkanes (circular structures), and branched alkanes (carbon chains substitute for a few hydrogen atoms along the straight-chain alkanes) (Table 1). Aromatics, consisting of planar unsaturated rings, usually occupy about $30 \%$ of the crude oil's mass [11]. Aromatics can be placed into two categories. The first of which are single ringed aromatics, also known as monoaromatics, comprising of only four compounds: benzene, toluene, ethylbenzene, and xylenes (BTEX). The second category encompasses the polycyclic aromatic hydrocarbons (PAHs), containing two or more rings. Generally, BTEX and PAHs are more soluble in water than saturates with the same number of carbons [12]. Table 1 presents a few hydrocarbons found in crude oil.

Resins and asphaltenes make up the smallest weight percentage of most crude oils (about 10\%) [11], and they are responsible for the oil's black color. Unlike saturates and aromatics, resins and asphaltenes are not hydrocarbons since they contain other elements such as sulfur, nitrogen, and oxygen. There is no general formula for asphaltenes or resins [11].

Crude oils can be classified based on their densities, expressed as degrees of API gravity [11]. Generally, lighter oils (high API) are more valuable [13]. In addition, crude oil can be classified relative to its sulfur content [14]. Oils with a sulfur content equal to or above $0.5 \%$ are considered sour, while those with a sulfur content less than $0.5 \%$ are sweet [14]. Usually, sweet oils are more favorable [11].

\section{OIL WEATHERING}

When crude oil is released into the environment, it goes through various weathering processes, such as evaporation, dissolution, and photooxidation. Generally, a large fraction (10\% to $30 \%)$ of light to medium oil can evaporate if left stranded on land or floating on a body of water, causing the crude to become heavier and darker in color [15]. Light oils are found in the Gulf of Mexico, and medium oils are found in Alaska. Crude oil may also be subjected to dissolution, where about $1-5 \%$ of the oil's aromatic compounds dissolve in water [16]. As for photooxidation, some of the aromatics and asphaltenes absorb heat from the sun to set off several chemical reactions, during which hydrocarbons combine with oxygen to form resins [17]. Photooxidation does not remove oil from the environment, but transforms some of its com- 
pounds; mostly aromatics [18].

\section{OIL BIODEGRADATION}

Crude oil has existed for millions of years, allowing for the evolution of microorganisms that can readily biodegrade petroleum hydrocarbons [19]. Such microorganisms are ubiquitous in the environment, mostly in ecosystems where crude oil exists naturally (e.g., deep-sea oil seeps, oil reservoirs, oil seeps in lakes, etc.).

The simplified biodegradation reaction under aerobic conditions is given by: $\mathrm{CxHy}+(x+y / 4) \mathrm{O} 2=x \mathrm{CO} 2+\mathrm{y} / 2(\mathrm{H} 2 \mathrm{O})$. Usually, substrates (hydrocarbons) are biodegraded through a series of steps by microorganisms using specific metabolic pathways. Generally, biodegradation can remove a relatively large fraction of hydrocarbons compared to weathering.

Many factors impact the oil biodegradation rate, including, but not limited to, the oil's API gravity, temperature, availability of nutrients, salinity, $\mathrm{pH}$, and the surface area of the oil particles [20]. While biodegradation can occur in many temperatures ranging from below $0^{\circ} \mathrm{C}$ to above $80^{\circ} \mathrm{C}$, its rate is highest in warm waters with a temperature of $26^{\circ} \mathrm{C}$ to $35^{\circ} \mathrm{C}[15$, 20]. The biodegradation rate of crude oil is much larger under aerobic conditions relative to anaerobic biodegradation [20]. Hence, oil at the surface or subsurface of the sea will degrade much faster than oil that is buried within sediments [21, 22]. While microorganisms use hydrocarbons for energy, they also need nutrients such as nitrogen, phosphorus, and iron for reproduction [22]. The rate of biodegradation will increase as microorganisms' abundance increase; hence, nutrients that promote growth will also promote the breakdown of hydrocarbons [22]. Furthermore, lighter oils will degrade faster than heavy oils [22]. Moreover, the larger the oil-water's interfacial surface area, the more access microorganisms have to the oil [23]. Therefore, dispersing oil floating on water (oil slicks) by using dispersants is recommended [24]. Dispersants (i.e., chemical surfactants) break down large oil slicks into small droplets, therefore increasing the oil-water's interfacial surface area [25].

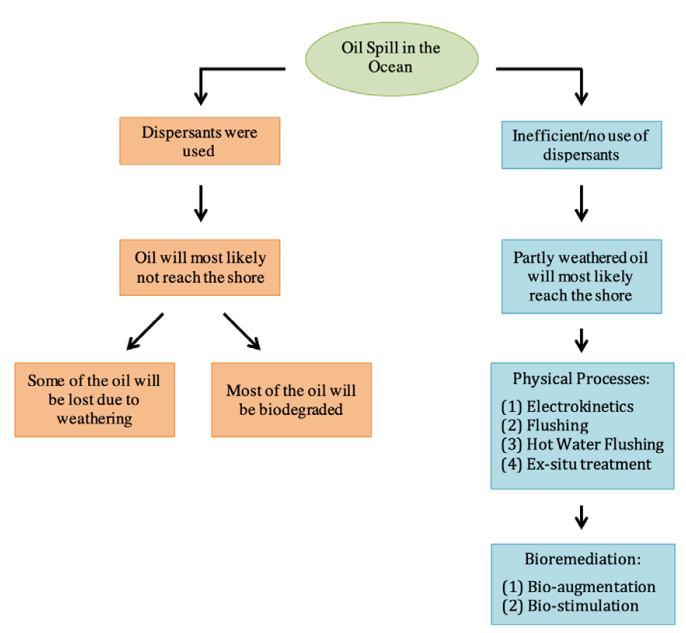

Figure 1. Flowchart displaying approaches for beach remediation if an oil spill occurred.

Table 2. Pros and Cons of Beach Remediation Techniques

\begin{tabular}{|c|c|c|c|c|}
\hline $\begin{array}{c}\text { Remediation } \\
\text { technique }\end{array}$ & $\begin{array}{c}\text { Type of } \\
\text { remediation } \\
\text { technique }\end{array}$ & Pros & Cons & References \\
\hline $\begin{array}{l}\text { Flushing and Hot } \\
\text { Water Flushing }\end{array}$ & Physical & $\begin{array}{l}\text { Considered to be } \\
\text { effective (removing } \\
\text { the majority of the } \\
\text { spilled oil) }\end{array}$ & $\begin{array}{c}\text { Threaten plant and } \\
\text { wildlife; may move } \\
\text { oil deeper into the } \\
\text { sediment }\end{array}$ & $\begin{array}{l}{[30]} \\
{[31]}\end{array}$ \\
\hline Ex-situ treatment & Physical & $\begin{array}{l}\text { Guarantee that } \\
\text { most of the oil is } \\
\text { removed }\end{array}$ & $\begin{array}{l}\text { Very costly; requires } \\
\text { a lot of labor. Highly } \\
\text { disruptive for the } \\
\text { environment }\end{array}$ & {$[32]$} \\
\hline Biostimulation & Biological & $\begin{array}{l}\text { Accelerates } \\
\text { biodegradation. } \\
\text { Usually cost- } \\
\text { effective }\end{array}$ & $\begin{array}{l}\text { Some nutrients (such } \\
\text { as oxygen) are } \\
\text { relatively expensive } \\
\text { to apply in the field }\end{array}$ & {$[33]$} \\
\hline Bioaugmentation & Biological & $\begin{array}{c}\text { Accelerates } \\
\text { biodegradation }\end{array}$ & $\begin{array}{l}\text { Not needed for most } \\
\text { beaches because they } \\
\text { already contain } \\
\text { hydrocarbon- } \\
\text { degraders }\end{array}$ & {$[33]$} \\
\hline
\end{tabular}




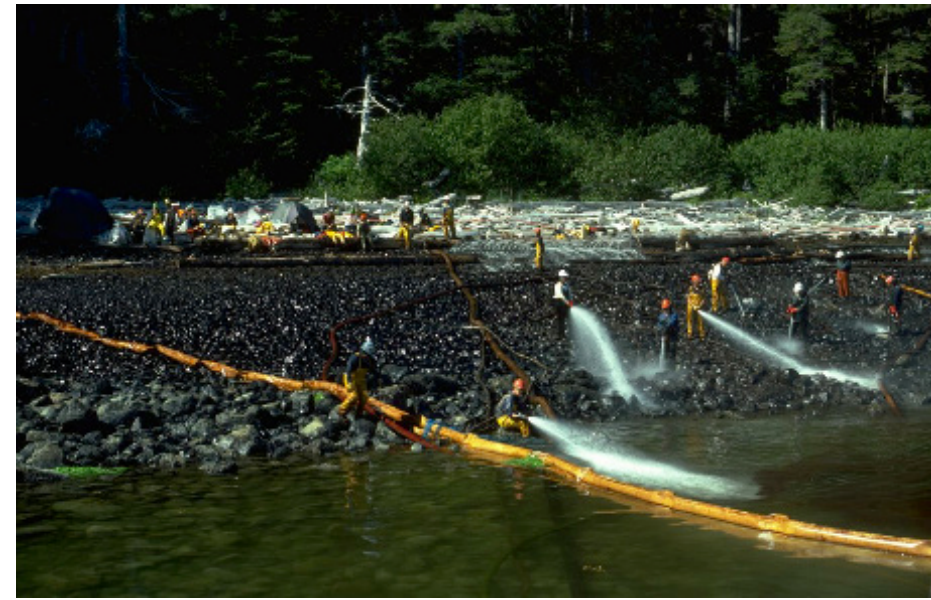

Figure 2. Low-pressure flushing for oil cleanup [26]

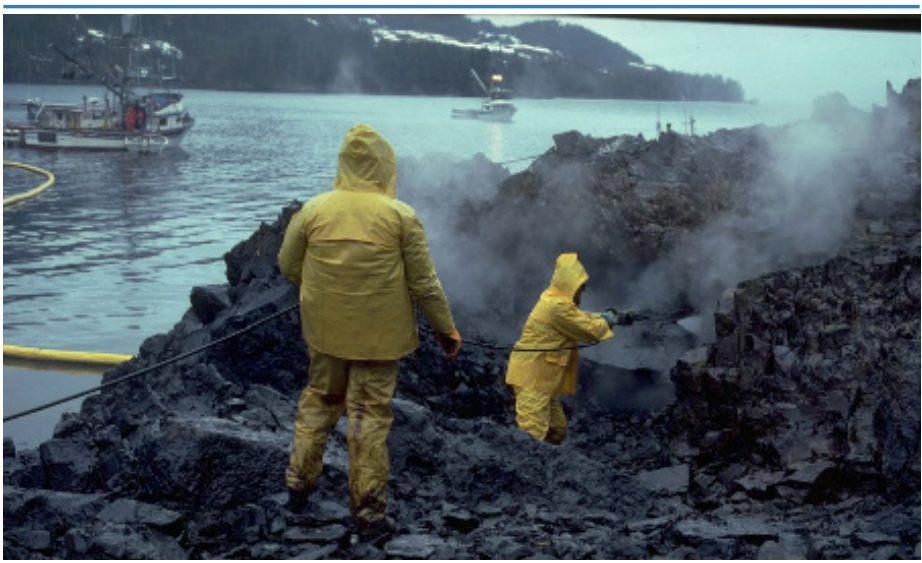

Figure 3. Hot water flushing for oil remediation [35]

\section{REMEDIATION OF OILED BEACHES}

The flowchart in Figure 1 details the best approaches for beach remediation if a spill occurs in the ocean and reaches the shoreline, as it did in the following events: the spills that occurred after the Gulf War [26], the Exxon Valdez, Erika, and Haven wrecks [5-7], and the blowout of the Deepwater Horizon and Ixtoc-1 wells $[9,27]$. When crude oil is spilled in the ocean, efforts should be made to remove it quickly. Ideally, this would occur through mechanical removal using skimmers - devices used to remove floating oil from the water surface. However, if the sea state is violent, dispatching skimmers might be too hazardous, and the skimmers are unlikely to work effectively. In this case, dispersants can be sprayed onto the oil to break the oil slick into smaller droplets that dilute within the water column [25], thus preventing the slick from reaching the shorelines where it would cause the most damage [28].

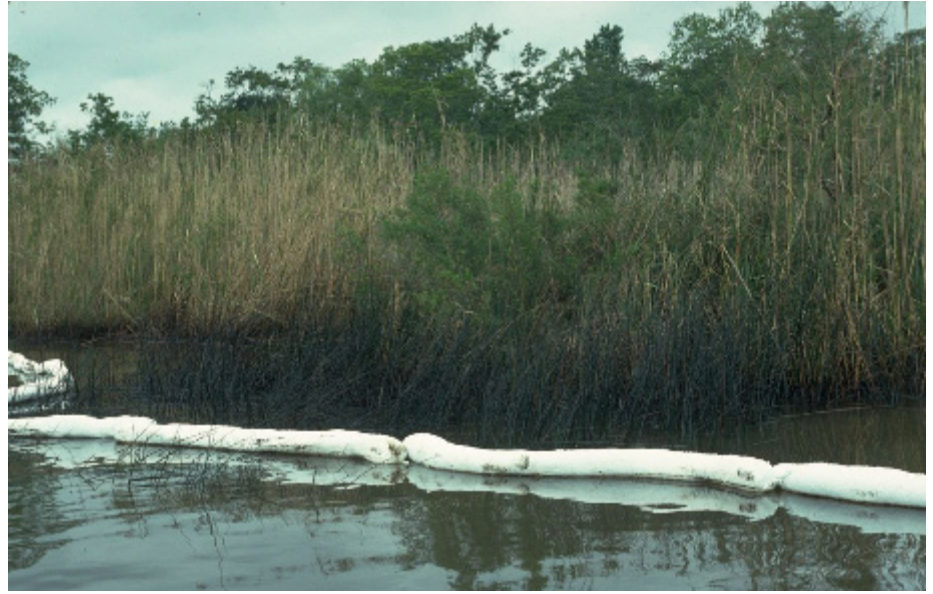

Figure 4. Sorbents used to absorb spilled oil [35]

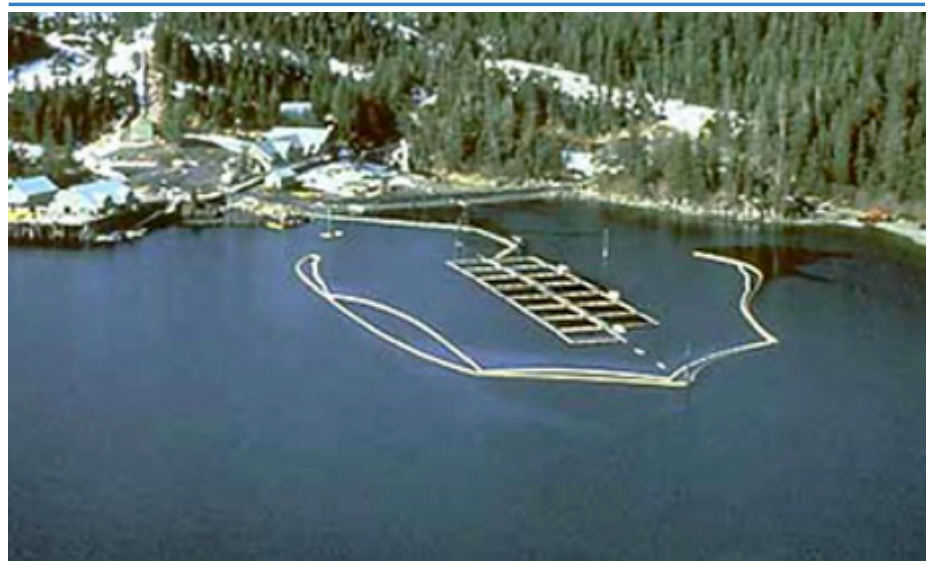

Figure 5. Booms used to retain oil from the Exxon Valdez oil spill [35]

If oil reaches the shoreline, several remediation techniques can be employed to remove it. The contaminated sediments of oiled beaches may be remediated ex-situ; meaning the sediments are physically excavated to be later treated or disposed of [29]. However, the large volumes of contaminated sediments make ex-situ treatment inefficient. If bioremediation is used, the oil-contaminated site can be treated in several ways: (1) bioaugmentation, in which hydrocarbon-degraders are introduced to a site to jump-start oil biodegradation, or (2) biostimulation, where nutrients are added to accelerate the biodegradation process [18]. In most situations, biostimulation is sufficient because the pore water within beaches already contains a substantial amount of hydrocarbon-degraders. Table 2 displays the pros and cons of several remediation methods, which are further explained in section 6 .

\section{METHODS FOR OIL CLEANUP}

In case an oil spill reaches the shoreline, there are various 


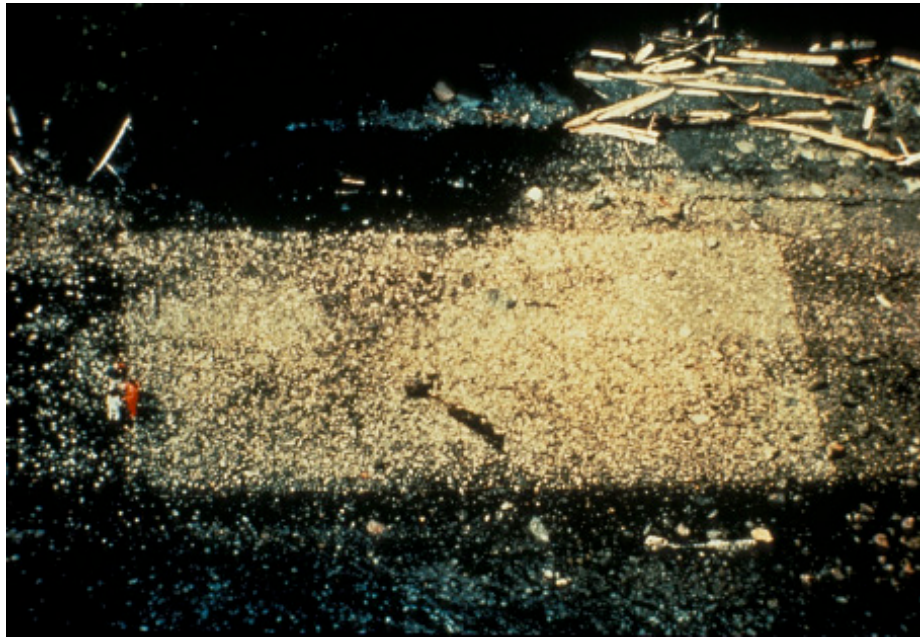

Figure 4. A Prince William Sound beach two weeks after being sprayed with fertilizer during bioremediation [36].

ways it can be removed. Excavating contaminated sediments can take place, but is harmful to the environment and expensive to treat offsite. Less harmful physical processes include flushing with cold or hot water and through the addition of surface washing agents [34]. Through flushing, oil from the shoreline is redirected using low-pressurized water to an area where it can be easily collected. Hot water flushing utilizes high-pressurized water at high temperatures $\left(27-100^{\circ} \mathrm{C}\right)$ [31]. Although considered less destructive than excavation, both flushing and hot water flushing can damage a shoreline's ecosystems [31]. Hot water flushing, specifically, eradicates plants and animals that come in contact with the hot pressurized water [31]. Figures 2 and 3 depict the processes of flushing and hot water flushing, respectively.

To prevent the oil from reaching the shore, certain equipment can be used, such as sorbents or booms that absorb or contain the spill. Sorbents are hydrophobic materials that act like sponges to soak up oil (Figure 4). Booms are adept at keeping oil spills from spreading or migrating towards the coastline (Figure 5). Both sorbents and booms are not harmful to the natural environment [31].

Crude oil can also be chemically or biologically removed using shoreline cleaners or bioremediation. Shoreline cleaners, such as surfactants, are typically used for oil that has been thoroughly weathered and cannot be removed by flushing. These cleaners react with the crude oil, breaking it down into a substance that can be collected by sorbents or contained by booms [31]. On the other hand, bioremediation is a process that enhances biodegradation. Bioremediation is accomplished either by biostimulation or bioaugmentation
$[33,36]$. While bioremediation is not the fastest beach remediation process, it is natural and non-destructive, hence, causing the least amount of stress upon natural habitats [31].

Bioremediation was considered on two occasions after the Exxon Valdez Oil Spill (EVOS). The first was performed immediately following the spill. Measurements of the pore water chemistry at shallow depths of the oil-contaminated beaches at Prince William Sound revealed that the nitrate and phosphate concentrations were too low for efficient oil biodegradation. Bioremediation was then pursued, in which 55 tons of nitrate in neat form were applied to the surface of the affected beaches during low tide $[23,37,38]$. The results showed that the biodegradation rate increased by ten-fold within the coastal sediments. The second bioremediation attempt was in 2007-2008, in which measurements of water chemistry within six oil-contaminated Prince William Sound beaches revealed that the limited availability of nutrients and oxygen was the primary factor for the lack of oil biodegradation [21, 39]. Consequently, Boufadel and Geng [8] conducted bioremediation studies on four Prince William Sound beaches where oxygenated water (hydrogen peroxide) and nutrients were injected, resulting in an increase in the biodegradation rate by four-fold. Figure 6 depicts a section of a contaminated beach in Prince William Sound two weeks after being sprayed with an oleophilic fertilizer [36].

\section{CONCLUSION}

Crude oil is widely used around the globe. Inevitably, some oil gets spilled during production, transportation, or use. If a large spill occurs, the oil immediately manifests chemical and physical transformations such as evaporation, dissolution, and photooxidation processes collectively referred to as "weathering". In addition, biodegradation plays a substantial role in decomposing large amounts of spilled oil by relying on indigenous hydrocarbon-degraders.

When an oil spill occurs in the ocean, it is best to prevent the oil slick (oil floating on water) from reaching the shorelines by booming the oil and skimming it. But when mechanical means are arduous, responders may use dispersants to break the oil slicks into small droplets, which spread in the water column and eventually biodegrade. If the oil was not appropriately dispersed and reached the shoreline, one may use cold or hot water flushing and surface washing agents. Concomitantly, one may pursue bioremediation by creating 
a favorable environment for microorganisms to thrive and consume the oil through the addition of nutrients or cultivated hydrocarbon-degraders.

\section{REFERENCES}

1. U.S. Energy Information Administration (USEIA). Retrieved from https://www.eia.gov/tools/faqs/faq. php?id=709 (accessed November 15, 2020).

2. American Geosciences Institute (AGI). Transportation of Oil, Gas, and Refined Products. 2018 Jun. Retrieved from https://www.americangeosciences.org/geosciencecurrents/transportation-oil-gas-and-refined-products (accessed November 15, 2020).

3. Baffes, J. Oil spills on other commodities. Policy Research Working Papers: The World Bank. 2007 Nov. https://doi. org/10.1596/1813-9450-4333.

4. Aske N, Kallevik H, Sjöblom J. Determination of saturate, aromatic, resin, and asphaltenic (SARA) components in crude oils by means of infrared and near-infrared spectroscopy. Energy \& Fuels. 2001 Sep; 15(5):1304-1312. https://doi.org/10.1021/ef010088h.

5. Jézéquel R, Poncet F. The Erika Oil Spill, 10 Years After: Assessment of the natural weathering of the oil and natural recovery of vegetation. International Oil Spill Conference Proceedings (IOSC). 2011 Mar. American Petroleum Institute. https://doi.org/10.7901/2169-33582011-1-165.

6. Martinelli M, Luise A, Tromellini E, Sauer TC, Neff JM, Douglas GS. The M/C Haven oil spill: Environmental assessment of exposure pathways and resource injury. International Oil Spill Conference (IOSC). 1995 Feb. American Petroleum Institute. https://doi. org/10.7901/2169-3358-1995-1-679.

7. Taylor E, Reimer D. Oil persistence on beaches in Prince William Sound-A review of SCAT surveys conducted from 1989 to 2002. Marine Pollution Bulletin. 2008 Mar; 56(3):458-474. https://doi.org/10.1016/j. marpolbul.2007.11.008.

8. Boufadel MC, Geng X, Short J. Bioremediation of the Exxon Valdez oil in Prince William sound beaches. Marine pollution bulletin. 2016 Dec; 113(1-2):156-64. https://doi.org/10.1016/j.marpolbul.2016.08.086.

9. Michel J, Owens EH, Zengel S, Graham A, Nixon Z, Allard T, Holton W, Reimer PD, Lamarche A, White M, Rutherford N. Extent and degree of shoreline oiling: Deepwater Horizon oil spill, Gulf of Mexico, USA. PloS one. 2013 Jun; 8(6):e65087. https://doi.org/10.1371/ journal.pone.0065087.

10. Abou Khalil, C, Prince, VL, Prince, RC, Greer, CW, Lee, K, Zhang, B, Boufadel, MC. Occurrence and Biodegradation of Hydrocarbons at High Salinities. Science of The Total Environment. 2020; 143165. https://doi.org/10.1016/j. scitotenv.2020.143165.

11. Tissot BP, Welte DH. Petroleum formation and occurrence. Springer Science \& Business Media; 2013 Nov.

12. Hussar E, Richards S, Lin ZQ, Dixon RP, Johnson KA. Human health risk assessment of 16 priority polycyclic aromatic hydrocarbons in soils of Chattanooga, Tennessee, USA. Water, Air, \& Soil Pollution. 2012 Nov; 223(9):5535-5548. https://doi.org/10.1007/s11270-0121265-7.

13. Strubinger A, Ehrmann U, León V. Using the gas pycnometer to determine API gravity in crude oils and blends. Energy \& fuels. 2012 Nov; 26(11):6863-6868. https://doi.org/10.1021/ef301193x.

14. Fattouh Bassam, Andreas Economou. The Light SweetMedium Sour Crude Imbalance and the Dynamics of Price Differentials. Oxford Institute for Energy Studies. 2019. Retrieved from www.oxfordenergy.org/ publications/light-sweet-medium-sour-crude-imbalancedynamics-price-differentials/ (accessed November 25, 2020).

15. United States Environmental Protection Agency (USEPA). The Fate of Spilled Oil. 2016. Retrieved from www. archive.epa.gov/emergencies/content/learning/web/ html/oilfate.html (accessed November 15, 2020).

16. ITOPF. Weathering. 2018. Retrieved from https://www. itopf.org/knowledge-resources/documents-guides/fateof-oil-spills/weathering/ (accessed November 15, 2020).

17. Shankar R, Shim WJ, An JG, Yim UH. A practical review on photooxidation of crude oil: Laboratory lamp setup and factors affecting it. Water Research. 2015 Jan; 68:304315. https://doi.org/10.1016/j.watres.2014.10.012.

18. Prince RC, Lessard RR. Crude oil releases to the environment: natural fate and remediation options. Encyclopedia of Energy. 2004 Jan; 1:727-736. http:// faculty.tamucc.edu/plarkin/4292folder/Oil\%20Spill\%20 releases.pdf.

19. Prince RC, Nash GW, Hill SJ. The biodegradation of crude oil in the deep ocean. Marine pollution bulletin. 2016 Oct; 111(1-2):354-357. https://doi.org/10.1016/j. marpolbul.2016.06.087.

20. Atlas RM, Hazen TC. Oil biodegradation and bioremediation: a tale of the two worst spills in US history. 2011. https://doi.org/10.1021/es2013227.

21. Li, H, Boufadel, MC. Long-term persistence of oil from the Exxon Valdez spill in two-layer beaches. Nature Geoscience. 2010 Feb; 3:96. https://doi.org/10.1038/ ngeo749.

22. Hassanshahian M, Cappello S. Crude oil biodegradation in the marine environments. In Chamy R. Biodegradation-Engineering and Technology, Tech. 2013 Jun; 101-135. http://dx.doi.org/10.5772/55554.

23. Prince, RC, Bragg, JR. Shoreline Bioremediation Following the Exxon Valdez Oil Spill in Alaska. Bioremediation Journal. 1997 Apr; 1(2):97-104. https:// doi.org/10.1080/10889869709351324.

24. Jue M. Fluid Cuts: The Anti-visual Logic of Surfactants 
after Deepwater Horizon. Configurations. 2019 Nov; 27(4):525-544. https://doi.org/10.1353/con.2019.0034.

25. Lessard, RR, DeMarco, G. The significance of oil spill dispersants. Spill Science \& Technology Bulletin. 2000 Feb; 6(1): 59-68. https://doi.org/10.1016/S13532561(99)00061-4.

26. Fowler, SW, Readman, JW, Oregioni, BJ, Villeneuve, JP, McKay, K. Petroleum hydrocarbons and trace metals in nearshore Gulf sediments and biota before and after the 1991 war: an assessment of temporal and spatial trends. Marine pollution bulletin. 1993 Jan; 27:171-82. https:// doi.org/10.1016/0025-326X(93)90022-C.

27. Boufadel, MC, Wrenn, BA, Moore, BE, Boda, KJ, Michel, JA. Biodegradation assessment tool for decision on beach response. Proceedings of the International Oil Spill Conference. American Petroleum Institute. 2011 Jun. https://doi.org/10.7901/ 2169-3358-2011-1-348.

28. Wolfe, D, Michel, J, Hameedi, MJ, Payne, JR, Galt, JA, Watabayashi, G, Rice, S. The fate of the oil spilled from the Exxon Valdez. Environmental Science \& Technology. 1994; 28(13):560A-568A

29. Cunningham, CJ. Philp, JC. Comparison of bioaugmentation and bio-stimulation in exsitu treatment of diesel contaminated soil. Land Contamination and Reclamation. 2000 Oct; 8(4):261-9. http://doi.org/10.2462/09670513.575.

30. Zhou, Q, Sun, F, Liu, R. Joint chemical flushing of soils contaminated with petroleum hydrocarbons. Environment International. 2005 Aug; 31(6):835-839. https://doi.org/10.1016/j.envint.2005.05.039.

31. Walther III, HR. Clean Up Techniques Used for Coastal Oil Spills: An Analysis of Spills Occurring in Santa Barbara, California, Prince William Sound, Alaska, the Sea of Japan, and the Gulf Coast. 2014. Retrieved from https:// repository.usfca.edu/capstone/104 (accessed November 15, 2020).

32. Beškoski, VP, Gojgić-Cvijović, G, Milić, J, Ilić, M, Miletić, S, Šolević, T, Vrvić MM. Ex-situ bioremediation of a soil contaminated by mazut (heavy residual fuel oil)-A field experiment. Chemosphere. 2011 Mar; 83(1):34-40. https://doi.org/10.1016/j.chemosphere.2011.01.020.

33. Xu, Y, Lu, M. Bioremediation of crude oil-contaminated soil: comparison of different biostimulation and bioaugmentation treatments. Journal of hazardous materials. 2010; 183(1-3):395-401. https://doi. org/10.1016/j.jhazmat.2010.07.038.

34. Chen, C, Weng, D, Mahmood, A, Chen, S, Wang, J. Separation mechanism and construction of surfaces with special wettability for oil/water separation. ACS applied materials \& interfaces. 2019 Feb; 11(11):1100611027. https://doi.org/10.1021/acsami.9b01293.

35. National Oceanic and Atmospheric Administration Office of Response and Restoration (NOAA-ORR). Spill Cleanup Methods. Retrieved from https://response.restoration. noaa.gov/spill-cleanup-methods (accessed November 15, 2020).
36. Prince RC, Clark JR, Lindstrom JE. Field studies demonstrating the efficacy of bioremediation in marine environments. In Hydrocarbon and Lipid Microbiology Protocols. 2015; 81-93. Springer, Berlin, Heidelberg. https://doi.org/10.1007/8623_2015_172.

37. Bragg, JR, Prince, RC, Harner, EJ, Altas, RM. Effectiveness of bioremediation for the Exxon Valdez oil spill. Nature. 1994 Mar; 368:413-418. https://doi. org/10.1038/368413a0.

38. Atlas, R, Bragg, J. Bioremediation of marine oil spills: when and when not-the Exxon Valdez experience. Microbial Biotechnology. 2009 Feb; 2(2):213-221 https://doi.org/10.1111/j.1751-7915.2008.00079.x.

39. Boufadel, MC, Sharifi, Y, Van Aken, B, Wrenn, BA, Lee, $K$. Nutrient and oxygen concentrations within the sediments of an Alaskan beach polluted with the Exxon Valdez oil spill. Environmental Science and Technology. 2010; 44(19):7418-7424. https://doi.org/10.1021/ es102046n. 